\title{
Synthetic Studies of Carbohydrate Antibiotics
}

\section{Part III. Gas-Liquid Chromatography of Trifluoroacetyl Derivatives of Carbohydrates Including Cyclitols ${ }^{1)}$}

\author{
By Tamio Ueno, Norio Kurihara and Minoru Nakajima \\ Department of Agricultural Chemistry, College of Agriculture \\ Kyoto University, Kyoto \\ Received June 8, 1967
}

\begin{abstract}
The separation of carbohydrates and cyclitols by gas-liquid chromatography of their trifluoroacetyl (TFA) derivatives is described. TFA derivatives are readily formed in formamide containing sodium trifluoroacetate and trifluoroacetic anhydride without heating so that the chromatographic analyses can be made in a short time. Conditions are described for the chromatography of variety of carbohydrates including the mono- and disaccharides, simple glycosides, aminosugars, and cyclitols. The analyses have been made mostly with a silicone column (SE-52) and a fluorosilicone column (QF-1). Isothermal conditions are usually employed, but for a mixture with components of widely differing molecular weight, linear temperature-programmed procedures are performed.
\end{abstract}

\section{INTRODUCTION}

The gas-chromatographic analyses of carboydrates have been so far investigated generlly by using their O-methyl, ${ }^{2 !} \mathrm{O}$-acetyl, ${ }^{3)}$ and )-trimethylsilyl (TMS) derivatives. Among 1ese, the most easily prepared TMS derivaves are well separated at the lowest temeratures, and have been considered to be ue most satifactory derivatives for the gashromatography.

For the analyses of carbohydrate mixtures cluding cyclitols, especially their amino deriatives which often appear as a component $f$ the carbohydrate antibiotics, a more con-

1) Part II, S. Takahashi and M. Nakajima, This ournal, 31, 1082 (1967).

2) C. T. Bishop and F. P. Cooper, Can. J. Chem., 8, 388 (1960); E. Bayer and Widder, Anal. Chem., 6, $1452(1964)$.

3) S. W. Gunner, J. K. N. Jones and M. B. Perry, an. J. Chem., 39, 1892 (1961); H. G. Jones and A. B. Perry, ibid., 40, 1339 (1962); C. T. Bishop, P. Cooper and R. K. Murray, ibid., 41, 2245 (1963). 4) C. C. Sweeley, R. Bentley, M. Makita, W. W. lells, J. Am. Chem. Soc., 85, 2497, (1963); C. C. weeley and B. Walker, Anal. Chem., 36, 1461 (1964). venient derivative is desired, since some of the cyclitols are not so easily dissolved in pyridine to produce their TMS derivatives rapidly and quantitatively.

For the amino acids and peptides, Weygand and his coworkers ${ }^{5}$ have found an excellent volatility of their trifluoroacetyl derivatives and performed the gas-chromatographic analyses by using them. In this paper, we have applied their method to the carbohydrates, and found that the TFA derivatives showed the good separations at a much lower temperature than the corresponding methyl or TMS derivatiaves (see Table I).

Recently, Vilkas and his associates ${ }^{6}$ have alse described the versatility of the TFA derivatives for the gas-chromatographic analysis of the sugars. Our precedure is different from their's in using formamide as the solvent

5) F. Weygand, B. Kolb, A. Prox, M. A. Tilak and I. Tomida, Z. Physiol. Chem., 322, 38 (1960).

6) M. Vilkas, Hiu-I-Jan, G. Boussac and M.-C. Bonnard, Tetrahedron Letters, 14, 1441 (1966). 
Table I. Comparison of the Retention Time of THE TFA, METHYL AND TMS DERIVATIVES

\begin{tabular}{|c|c|c|c|c|c|}
\hline \multicolumn{2}{|l|}{ Column } & \multicolumn{2}{|l|}{ SE-52 } & \multirow{2}{*}{$\begin{array}{l}Q F-1 \\
110\end{array}$} & \multirow{2}{*}{$\begin{array}{l}\text { N. G.S. } \\
150\end{array}$} \\
\hline Temperature $\left({ }^{\circ} \mathrm{C}\right)$ & 110 & 140 & 200 & & \\
\hline Carrier Gas, $\mathrm{N}_{2}(\mathrm{ml} / \mathrm{min})$ & 28.5 & 25.0 & 19.5 & 120.0 & 30.0 \\
\hline myo-Inositol (TFA) & $2.5 \mathrm{~min}$ & $0.9 \mathrm{~min}$ & - & $2.7 \mathrm{~min}$ & - \\
\hline Methyl $\alpha$-D-glucopyranoside (TFA) & 8.0 & 2.7 & - & 4.3 & - \\
\hline myo-Inositol (Me) & - & 8.5 & - & - & $14.2 \mathrm{~min}$ \\
\hline Methyl $\alpha$-D-glucopyranoside (Me) & - & 7.8 & - & - & 15.6 \\
\hline myo-Inositol (TMS) & - & - & $13.0 \mathrm{~min}$ & - & 16.3 \\
\hline Methyl $\alpha$-D-glucopyranoside (TMS) & - & - & 5.7 & - & 11.9 \\
\hline
\end{tabular}

for the trifluoroacetylation and requires a much shorter time for the analysis.

\section{EXPERIMENTAL}

Materials. Most of the mono- and disaccharides used in this study were commercially available. 6Amino-6-deoxy-D-glucose and its derivatives were prepared according to Cramer et al.,7) and methyl 3-amino-3-deoxy- $\beta$-D-glucopyranoside and methyl 3amino-3-deoxy- $\alpha$-D-mannopyranoside were according to Baer et al.8) Most of inositols and aminocyclitols were synthesized by the method of Nakajima et al.,93 except for scyllo-and epi-inositol which were prepared according to the procedure of Posternak et al.10) TFA anhydride was prepared by treating trifluoroacetic acid with phosphorus pentoxide. Sodium trifluoroacetate was prepared by neutralization of $1 \mathrm{~N}$ trifluoroacetic acid with $1 \mathrm{~N}$ sodium hydroxide ( $\mathrm{pH}$ to 7 ) and by evaporation of the resulting solution. Addition of benzene and evaporation was repeated several times to remove a trace of water. The crystals obtained were dried at $100^{\circ} \mathrm{C}$ at a reduced pressure and used for the reaction. Penta-O-methyl- $\alpha$-D-glucose was prepared from methyl $\alpha$-D-glucopyranoside by

7) F. Cramer, H. Otterbach and H. Springmann, Chem. Ber., 92, 384 (1959).

8) H. H. Baer and H. O. L. Fischer, J.Am. Chem. Soc., 82, 3709 (1960); H. H. Baer, ibid., 84, 83 (1962); Chem. Ber., 93, 2865 (1960); J. Am. Chem. Soc., 83, 1882 (1961).

9) M. Nakajima, I. Tomida, N. Kurihara and S. Takei, Chem. Ber., 92, 173 (1959); M. Nakajima, N. Kurihara and A. Hasegawa, ibid., 95, 141 (1962); M. Nakajima, A. Hasegawa and F. W. Lichtenthaler, Ann., 680, 21 (1964).

10) T. Posternak, Helv. Chim. Acta, 24, 1045 (1941); D. Reymond, ibid., 40, 492 (1957); T. Posternak, ibid., 19, 1333 (1936).

the methylation method of Hakomori.11) Hexa-Omethyl-myo-inositol was prepared by the method of Kuhn et al.12) TMS derivatives were prepared by the procedure of Sweeley et al.4) Solvents were reagent grade and were used as supplied unless specially noted.

The column packings were commercially available preparations. Ten per cent N. G.S. on acid treated and silanized Chromosorb W ( $80 \sim 100$ meshes) was obtained from Nishio Kogyo Co., Ltd.; and 3\% SE-52 on acid treated and silanized Chromosorb W (80 100 meshes) and $1 \%$ QF-1 on Diasolid $\mathrm{H}$ (30 50 meshes) were obtained from Nihon Chromato Kogyo Co., Ltd.

Procedures. The general procedure of trifluoroacetylation is as follows. One $\mathrm{mg}$ of the dry sample of a free sugar or a related substrate and $0.3 \mathrm{mg}$ of sodium trifluoroacetate were dissolved in $0.05 \mathrm{ml}$ of formamide by heating. The solution was cooled to room temperature, and $0.2 \mathrm{ml}$ of trifuoroacetic anhydride was gradually added with cooling in an ice bath, and the whole mixture was left for 10 minutes at room temperature. Then 1 to $2 \mu$ of the resulting solution was injected by a microsyringe into the gas chromatographic equipment.

Nature of the trifluoroacetylated products. In order to isolate and characterize the trifluoroacetyl derivatives, a larger amount of the starting material was used. The following five materials were selected as model compounds, and two procedures of trifluoroacetylation were compared: (A) the Bourne's method ${ }^{18\}}$ and (B) the present method. Bourne and his co-

11) S. Hakomori, J. Biochemistry, 55, 205 (1964). 12) R. Kuhn and H. Trischmann, Chem. Ber., 96, 284 (1963).

13) E.J. Bourne, C. E. M. Tatlow and J. G. Tatlow, J. Chem. Soc., 1950, 1367; E. J. Bourne, M. Stacey, C. E. M. Tatlow and J. C. Tatlow, ibid., 1951, 826. 
orkers have prepared the TFA derivatives for other urposes than gas-chromatographic analysis.

1) Hexa-0-TF A-myo-inositol. A) In a $10 \mathrm{ml}$ und bottomed flask fitted with a reflux condenser id a calcium chloride tube, $90 \mathrm{mg}$ of dry myo-inositol, I mg of sodium trifluoroacetate and $2.5 \mathrm{ml}$ of trifluoroetic anhydride were placed. The mixture was intly refluxed in an oil bath with occasional shaking

$60 \sim 70^{\circ} \mathrm{C}$ for about 30 minutes. The whole terials went into solution, and the heating was ntinued for additional 10 minutes. After the solujn was cooled down to room temperature, it was ansferred into an appropriate sublimation apparatus, id excess anhydride and acid formed were removed a reduced pressure. The sublimation was conhcted at $140 \sim 160^{\circ} \mathrm{C}(18 \mathrm{mmHg})$. Two hundred and tty $\mathrm{mg}$ of fine colorless crystals of m.p. $140^{\circ} \mathrm{C}$ as obtained. Yield $63 \%$. The IR spectrum is own in Fig. 1.

B) Forty $\mathrm{mg}$ of dry myo-inositol and $15 \mathrm{mg}$ of dium trifluoroacetate were dissolved in $0.5 \mathrm{ml}$ of rmamide with gently heating. After the solution as cooled down to room temperature, $2.0 \mathrm{ml}$ of fluoroacetic anhydride was slowly added with ice
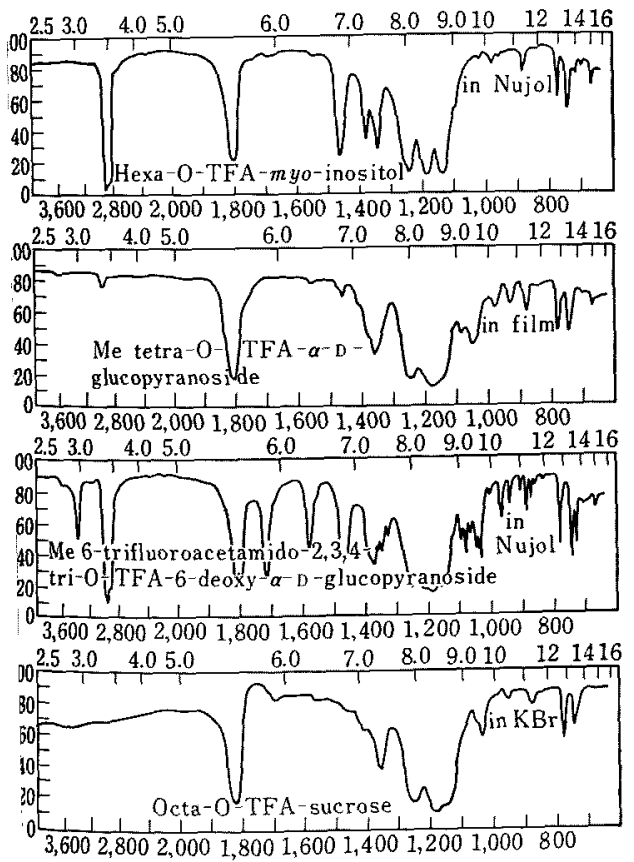

FIG. 1. IR Spectra of the TFA Derivatives. cooling. Then a violent reaction occurred and the mixture began to reflux. After the reflux ceased, the solution was kept at room temperature for 10 minutes. After addition of a few $\mathrm{ml}$ of sym.tetrachloroethane, the solution was concentrated in vacuo. The resulting syrup was dissolved in $1 \mathrm{ml}$ of trifluoroacetic anhydride and set aside in a desiccator over night. Colorless needles ( $84 \mathrm{mg}, \mathrm{m} . \mathrm{p} .140^{\circ} \mathrm{C}$ ) were obtained. Mixed m.p. and IR spectra confirmed its identity with the product of (1) (A). The mother liquor $(1 \sim 2 \mu 1)$ was injected into the gas chromatographic equipment. A single peak was observed. the retention time of which was the same as that of the above mentioned crystalline hexa-O-TFA-myo-inositol dissolved in tetrahydrofuran (except for the solvent peak having a very short retention time).

2) Methyl tetra-0-TF A- $\alpha$-D-glucopy ranoside. A) Four hundred and fifty $\mathrm{mg}$ of methyl $\alpha$-D-glucopyranoside, $150 \mathrm{mg}$ of sodium trifluoroacetate and $5 \mathrm{ml}$ of trifluoroacetic anhydride were treated as described in (1)(A). After distillation at $180^{\circ} \mathrm{C}$ (bath temperature) and $18 \mathrm{mmHg}, 910 \mathrm{mg}$ of a syrup was obtained. Yield $43 \%$. It was dissolved in anhydrous tetrahydrofuran and injected into the gas chromatographic equipment, showing a single peak beside the solvent peak. The IR spectrum is shown in Fig. 1.

B) Methyl $\alpha$-D-glucopyranoside in formamide was treated as described in ( 1 ) (B). The resulting solution was analyzed gas-chromatographically and a single peak was observed on the gas chromatogram having the same retention time as the above identified methyl tetra-O-TFA- $\alpha$-D-glucopyranoside.

3) Methyl 6-deoxy-6-trifluoroacetamido-2,3,4-triO-TFA- $\boldsymbol{\alpha}$-D-glucopyranoside. A) Eighty $\mathrm{mg}$ of methyl 6-amino-6-deoxy- $\alpha$-D-glucopyranoside hydrochloride, $20 \mathrm{mg}$ of sodium trifuoroacetate and $2 \mathrm{ml}$ of trifuoroacetic anhydride were treated as described in (1) (A). After sublimation at $120^{\circ} \mathrm{C}(18 \mathrm{mmHg})$, $180 \mathrm{mg}$ of needles (85\%) were obtained. M. p. $98^{\circ} \mathrm{C}$. The IR spectrum is in Fig. 1.

B) In formamide, methyl 6-amino-6-deoxy- $\alpha$-Dglucopyranoside hydrochloride was trifluoroacetylated as described in (1) (B). The solution was examined gas-chromatographically and showed a sigle peak at the same retention time as that of the sample prepared by the procedure, (3) (A).

4) Octa-0-TFA-sucrose. A) One hundred $\mathrm{mg}$ of sucrose, $30 \mathrm{mg}$ of sodium trifluoroacetate, and $20 \mathrm{ml}$ of trifluoroacetic anhydride were treated as described in (1) (A). After sublimation at $180^{\circ} \mathrm{C}, 170 \mathrm{mg}$ of 
colorless crystals $(77 \%)$ were obtained. The IR spectrum is shown in Fig. 1.

B) In formamide, sucrose was trifluoroacetylated as described in (I) (B). The solution was examined gas-chromatographically, and showed a single peak at the same retention time with that of the sample prepared by the procedure (4) (A).

5) Octa-0-TF A- $\alpha$ and $\beta$-maltose. A) After 3 hours reflux of a mixture of maltose, sodium trifluoroacetate and trifluoroacetic anhyride, there was obtained a gummy substance. The soluble part was examined gas-chromatographically, but no peak was observed corresponding to octa-O-TFA-maltose.

B) Forty $\mathrm{mg}$ of malose monohydrate and $15 \mathrm{mg}$ of sodium trifluoroacetate were dissolved in $0.5 \mathrm{ml}$ of formamide. To the solution, $2 \mathrm{ml}$ of trifluoroacetic anhydride was added causing a violent reaction. After standing 10 minutes at room temperature, the solution was analysed gas-chromatographically. Two peaks having very close retention times were observed which should correspond to the $\alpha$ and $\beta$-anomers.

Gas Chromatography. Two instruments were used for the gas-chromatographic analysis: the HitachiPerkin-Elmer Model F-6 and the Yanagimoto Model $3 \mathrm{D}$; both of which were attached with hydrogen flame ionization detedctors and employed U-shaped stainless steel columns, $1 \mathrm{~m}$ length by $3 \mathrm{~mm}$ or $5 \mathrm{~mm}$ i. d.

As the most useful nonpolar liquid phase, 3\% SE-52 was used for the analyses of all types of the derivatives: methyl, TMS and TFA derivatives. One per cent QF-1 was selected as a polar liquid phase for the analyses of TFA derivatives. When a more usual polar liquid phase was used such as N.G.S. or E.G.S., these derivatives were adsorbed and not eluted from the column. For the methyl and TMS derivatives, a $10 \%$ N.G.S. column was used without difficulty. A capillary column, $45 \mathrm{~m}$ length by $0.5 \mathrm{~mm}$ i.d. containing SE-30 (Hitachi-Perkin-Elmer) was also used for the separation of the seven isomers of inositol.

In general, flow rates for the packed column ranged about 20 to $30 \mathrm{ml}$ per minute, except for the QF-1 column, where the rates of $115 \sim 120 \mathrm{ml}$ per minute were employed.

\section{RESULTS AND DISCUSSION}

\section{The Trifluoroacetylation Reaction}

The preparation of the TFA derivatives of some carbohydrates and related substances was first described by Bourne et al., who reported all of the free hydroxyl groups in the carbohydrates were completely trifluoroacetylated by refluxing for about half an hour with trifluoroacetic anhydride and sodium trifluoroacetate. A TFA derivative of desosamine was reported by Newman, ${ }^{14)}$ who employed anhydrous ether as a solvent for this reaction. Recently, Vilkas et al. ${ }^{61}$ achieved trifluoroacetylation of carbohydrates with trifluoroacetic anhydride and sodium trifluoroacetate in acetonitrile at $50 \sim 60^{\circ} \mathrm{C}$, and investigated the gas-chromatographic separation of these TFA derivatives.

The reaction procedure described in this paper does not require so much time as those described so far, and besides, it can be widely applied to various carbohydrates. This procedure is different from others in employing formamide as the solvent. It solubilized all the carbohydrates examined, and the reaction in this solvent occurred very rapidly without heating. During the reaction, trifluoroacetylformamide first formed would be considered to serve as an excellent trifluoroacetylating agent; since Ogata ${ }^{151}$ reported that the imides of monobasic acids served often as a very good acylating agent of alcohols.

Since the TFA derivative of an authentic sample examined except for the free reducing sugars showed always a single peak, it appears that all of the free hydroxyl and amino groups of the sample were converted to the corresponding TFA derivetives. This conclusion was also confirmed by the gas-chromatography of the isoloted products by the method of Bourne et al. Besides, the isolated TFA derivatives showed reasonable IR spectra, having the absorptions of $\mathrm{CF}_{3}$ at $1300 \sim 1100 \mathrm{~cm}^{-1}$, and ester carbonyl at about $1800 \mathrm{~cm}^{-1}$ (and amide absorptions in case of 6 -aminoglucose derivative), and no absorption corresponding to $\mathrm{OH}$ group(s). (See Fig. 1).

For the TFA derivatives of free reducing

14) H. Newman, J. Org. Chem., 30, 1287 (1965).

15) T. Ogata, Bull. Chem. Soc. Japan, 37, 11 7 (1964). 
sugars, two peaks of very close retention times were usually observed, and they are reasonably considered to correspond to those of the $\alpha$ and $\beta$-anomers.

\section{Separation of Representative Carbohydrates and} Cyclitols

Since each TFA derivative of some carbohydrates showed a good peak at a lower temperature by gas chromatography, we have further investigated some more representative carbohydrates and cyclitols. As shown in Tables II, III and IV, the monosaccharides, inositols and aminocyclitols can be separated at $110^{\circ} \mathrm{C}$.

The gas-chromatographic separation of inositol isomers has been studied by two groups of workers who employed the hexaacetyl derivatives $^{161}$ and the hexa-TMS derivatives. ${ }^{17}$

Table II. Relative Retention Time of the TFA DERIVATIVES OF MONOSACCHARIDES AND METHYL GLUCOPYRANOSIDES

$\begin{array}{lll}\text { Methyl } \alpha \text {-D-glucopyranoside } & 3.20 & \\ \text { Methyl } \beta \text {-D-glucopyranoside } & 3.48 & \\ \text { D-Glucose } & 1.34 & 2.07 \\ \text { D-Mannose } & 1.04 & - \\ \text { myo-Inositol } & 1.00(2.5 \mathrm{~min} .) & \end{array}$

SE-52-110 ${ }^{\circ} \mathrm{C}$; Carrier, $\mathrm{N}_{2} 28.5 \mathrm{ml} / \mathrm{min}$

Table III. Relative Retention Time of the TFA DERIVATIVES OF INOSITOL ISOMERS

\begin{tabular}{llll}
\multicolumn{1}{c}{ Column } & SE-52 & SE-30 & QF-1 \\
Temperature $\left({ }^{\circ} \mathrm{C}\right)$ & 110 & 110 & 110 \\
Carrier, $\mathrm{N}_{2}(\mathrm{ml} / \mathrm{min})$ & 28.5 & 4.35 & 120 \\
neo & 0.37 & 0.67 & 0.48 \\
rac & 0.40 & 0.64 & 0.60 \\
muco & 0.55 & 0.80 & 1.03 \\
allo & 0.64 & 0.87 & 1.18 \\
mya & 1.00 & 1.00 & 1.00 \\
& $(2.5 \mathrm{~min})$ & $(5.7 \mathrm{~min})$ & $(3.0 \mathrm{~min})$ \\
scyllo & 1.56 & 1.69 & 1.48 \\
spi & 3.33 & 2.78 & 2.98
\end{tabular}

\footnotetext{
16) Z.S. Krzeminski and S.J. Angyal, J. Chem. Sot., 1962, 3251 .

17) Y.C. Lee and C. E. Ballou, J. Chromatography, [8, 147 (1965).
}

TABLe IV. Relative Retention Time of THE TFA DERIVATIVES OF AMINOCYCLITOLS

$\begin{array}{lll}\quad \text { Column } & \text { SE-52 } & \text { QF-1 } \\ \text { Temperature }\left(\mathrm{C}^{\circ}\right) & 110 & 120 \\ \text { Carrier, } \mathrm{N}_{2}(\mathrm{ml} / \mathrm{min}) & 28.5 & 115 \\ \text { scyllo-Inosamine } & 1.06 & - \\ \text { allo-Inosamine-1 } & 3.07 & 5.37 \\ \text { 1-Deoxy-allo-inosamine-5 } & 2.02 & 3.83 \\ \text { 3-Deoxy-epi-inosamine-1 } & 8.73 & 8.23 \\ \text { Dihydroconduramine-F-4 } & 6.06 & 5.57 \\ \text { myo-Inositol } & 1.00 & 1.00 \\ & (2.5 \mathrm{~min}) & (1.8 \mathrm{~min})\end{array}$

Table V. Relative Retention Time of the TFa DERIVATIVES OF AMINO SUGARS AND Their METhyl GLycosides

Methyl 6-amino-6-deoxy- $\alpha$-D- $\quad 1.00$ glucopyranoside (7.6 min)

Methyl 6-acetamido-6-deoxy$\alpha$-D-glucopyranoside $\quad 1.08$

Methyl 3-amino-3-deoxy$\beta$-D-glucopyranoside $\quad 0.92$

Methyl 3-amino-3-deoxy$\boldsymbol{\alpha}$-D-mannopyranoside $\quad 0.51$

6-Amino-6-deoxy-D-glucose $\quad 0.53$

2-Acetamido-2-deoxy-D-glucose $\quad 0.37 \quad-$

2-Amino-2-deoxy-D-glucose $\quad 0.30$

0.50

$\mathrm{SE}-52140^{\circ} \mathrm{C}$; Carrier, $\mathrm{N}_{2} 28.5 \mathrm{ml} / \mathrm{min}$

$$
\begin{gathered}
\text { TABle VI. Relative Retention Time } \\
\text { of The TFA Derivatives } \\
\text { of Disaccharides }
\end{gathered}
$$

\begin{tabular}{llr} 
Sucrose & $1.0(6.1 \mathrm{~min})$ & \\
Trehalose & 1.54 & \\
Lactose & 1.61 & 2.18 \\
Maltose & 1.20 & 1.36 \\
Cellobiose & 1.22 & 1.56 \\
\multicolumn{2}{c}{$\mathrm{SE}-52160^{\circ} \mathrm{C}$, Carrier, } & $\mathrm{N}_{2} 23.1 \mathrm{ml} / \mathrm{min}$
\end{tabular}

It is interesting that the elution order of the TFA derivatives (Table III) was very similar to that of the hexaacetyl derivatives (ester), but different from that of the TMS derivatives (ether).

Aminosugars can be analyzed at $140^{\circ} \mathrm{C}$ (Table V), and disaccharides at $160^{\circ} \mathrm{G}$ (Table VI). This temperature required for separating the TFA derivatives of disaccharides was much 
lower than that used for the TMS derivative. ${ }^{\text {") }}$

Linear Temperature-programmed Separation of a Mixture of the TFA Derivatives of Carbohydrates

From the foregoing data of the separation, it was expected that the TFA derivatives of mixtures of monosaccharides, aminosugars, disaccharides, inositols and aminocyclitols could be separated between $100^{\circ} \mathrm{C}$ and $200^{\circ} \mathrm{C}$. A model of a mixed sample containing myoinositol, methyl $\alpha$-D-glucopyranoside, methyl $\beta$-D-glucopyranoside, methyl 6-amino-6-deoxy$\alpha$-D-glucopyranoside, sucrose, and trehalose was trifluoroacetylated and examined gas-chromatographically. A chromatogram shown in Fig. 2 was obtained by a programmed operation for temperature increase of $5^{\circ} \mathrm{C}$ per minute from $100^{\circ} \mathrm{C}$ to $200^{\circ} \mathrm{G}$, and all of the

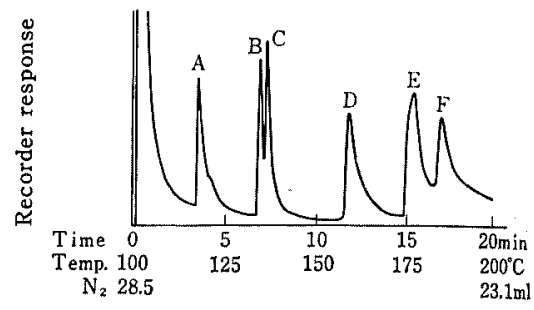

FIG. 2. Linear Temperature-programmed Separation of the TFA Derivatives of Representative Carbo. hydrates.
A. myo-Inositol
B. Methyl $\alpha$-D-glucopyranoside
C. Methyl $\beta$-D-glucopyranoside
D. Methyl 6-amino-6-deoxy- $\alpha$-D-glucopyranoside
E. Sucrose
F. Trehalose

peaks in the chromatogram were identified from the data shown in Table VII.

Table ViI. Relative Retention Time of Miscellaneous TFa Derivatives (SE-52)

$\begin{array}{llll}\text { Temperature }\left({ }^{\circ} \mathrm{C}\right) & 110 & 140 & 160 \\ \text { Carrier, } \mathrm{N}_{2}(\mathrm{ml} / \mathrm{min}) & 28.5 & 25.0 & 23.1 \\ \text { myo-Inositol } & 1.00(2.5 \mathrm{~min}) & 1.00(0.9 \mathrm{~min}) & 1.00(0.6 \mathrm{~min}) \\ \text { Methyl } \alpha \text {-D-glucopyranoside } & 3.20 & 3.00 & 2.17 \\ \text { Methyl } \beta \text {-D-glucopyranoside } & 3.48 & 3.22 & 2.42 \\ \text { Methyl 6-amino-6-deoxy- } \alpha \text {-D-glucopyranoside } & - & 9.11 & 5.79 \\ \text { Sucrose } & - & - & 10.01 \\ \text { Trehalose } & - & - & 15.38\end{array}$

